\title{
Historical Study on the Relation between Ancient Chinese Cuju and Modern Football
}

\author{
Xiaoxue Liu ${ }^{1}$, Yanfen Zhang ${ }^{2}$, and Xuezhi Ma ${ }^{3}$ \\ ${ }^{1}$ Department of Physical Education, China University of Geosciences, Xueyuan Road, Haidian \\ District, Beijing, P. R. China \\ ${ }^{2}$ Department of Life Sciences; Xinxiang University, Xinxiang Henan Province, Eastern Section of \\ Hua Lan Road, Hongqi District, Xinxiang City, Henan, China \\ ${ }^{3}$ Beijing Sport University Wushu School, Information Road, Haidian District, Beijing, China \\ xxliu8888@aliyun.com,1421185078@qq.com,malaoshide21@sohu.com
}

Keywords: Ancient Chinese Cuju, Modern Football, Relationship, Development, The Same Origin

Abstract: This paper studies on the origin and development of Chinese Cuju through document retrieval. Born in the period of Dongyi civilization, Chinese Cuju began to take shape during the Spring and Autumn and Warring States Period, and gradually flourished during the Qin, Han, Tang and Song dynasties. Through the economic and cultural exchange between China and the West in the past ages, Cuju was introduced into Europe when Mongol expedited westward in Yuan Dynasty. Finally, it has become the modern football, which originated from ancient Chinese Cuju and developed from European competition rules and now is widely accepted and popular in the world.

\section{The Cultural Background of the Study}

On July 15th, 2004, Mr. Blatter, the president of FIFA (Fédération Internationale de Football Association) officially announced in the 3rd session of Soccerex Fair, that football originated in Zibo, the capital of Qi State during the Spring and Autumn Period of ancient China. Cuju (ancient football game) began in China, while modern football (eleven -player game) originated in England. So far scholars of various countries have begun to study their local football history, causing a new wave of research(Kitching, Gavin, 2015.). For example, some Australian scholars have studied Australian aboriginal inhabitants' contribution to the football sports(Gorman, Sean. Judd, Barry. Reeves, Keir. 2015.), and some scholars made research on the development history of football in Caribbean areas(Wood, David, 2015.). All of them have conducted in-depth historical and impressive researches on local football development. This paper, from the perspective of sports history, studies the development history of ancient Chinese Cuju, its spread in Asia and contribution to the development of modern football as well as its roles. This paper also analyzes the origin of modern football, and believes that ancient Chinese Cuju and the world football development are in the same strain, and Cuju has played a positive role in promoting the development of modern football.

Because ancient Chinese Cuju contains many basic skills of traditional Wushu, most of the 
ancient Chinese Cuju practitioners are excellent practitioners of Chinese Wushu. By studying the development and evolution of ancient Chinese Cuju, we can indirectly understand some development veins of ancient Chinese traditional Wushu.

\section{The Development History of Ancient Chinese Cuju}

\subsection{Historical Development of Ancient Chinese Cuju}

Ancient Chinese football is also called Cuju. According to historical records, the date of Cuju's origin could not be confirmed. There were dances themed by Cuju as early as the Shang period of ancient China about 3500 years ago. During the Warring States Period, collective Cuju games prevailed in folk. It is recorded in Bie Lu, written by Liu Xiang (an ancient Chinese scholar, 77 BC-6 BC), that Cuju, created by Yellow Emperor (a legendary ruler in ancient China), was said to originate in the Warring States Period(Liu Xiang, 1975.). However, all above are recorded according to legend, which cannot serve as historical materials. On the basis of existing materials, it is certain that Cuju was popular as a kind of recreational activities in the states of Qi and Chu during the Warring States Period of ancient China. On the grounds of Shih Chi, Treatise of Su Qin, Linzi (a city in Shandong Province, China) was prosperous and strong where people played various musical instruments, such as, Yu pipe, Se (a twenty-five-stringed plucked instrument, somewhat similar to the zither), lute, and Zhu (an ancient Chinese 13-stringed instrument), enjoying cockfights, dog racing, Liubo Game(Six-Throwing-Chopstick Board Game Set) and playing Cuju(Sima Qian, 1978.). It shows that many people of the Qi state enjoyed Cuju game and it took shape during the Han Dynasty of China. The Han Dynasty enjoyed unprecedented national strength and flourishing and advanced culture and art, while sports began to develop vigorously. Due to the royal family's efforts, Cuju, Touhu game, chess, hunting and other activities became popular, and folk Cuju activities were carried out in full swing. Tang Dynasty, in the heyday of feudal social development, boasted vast territory, strong national strength and prosperity, the most advanced economy and culture at the time in the world. The developed feudal economy provided a solid foundation for cultural development. At this point, Cuju activities entered into a new stage. Breakthroughs of ball-making techniques were made with using inflatable spheres. In addition, relatively complete rules of games were created, enhancing the entertainment and competitiveness of Cuju activities. During the Song Dynasty, the development of sports activities was affected by Neo-Confucianism thought. As a result, social morals became frail, and such competitive sports like Cuju gradually disappeared.

\subsection{The Intercultural Communication and Development of Ancient Chinese Cuju}

Some scholars have pointed out that the West Expedition led by Yuan Dynasty introduced ancient Chinese Cuju into Europe. In the 4th century BC, football was brought into the Middle East because of wars waged by the ruler of Alexander, King of Macedon of ancient Greek. After entering into Rome and other places, it gradually developed into a competitive game where the points are got by moving the ball to an opposing team's goal area. Since then, the game was spread to France because of the war. In 1066, it entered into England. The origin of Asian football can also be found clues from the evolution of ancient Chinese Cuju in the Tang Dynasty, when Chinese football games were introduced into Asian countries along with the booming of foreign trade. As a Japanese ancient book, 99 Rules of Cuju records, "Cuju originated in the Tang Dynasty."

A great book, A History of World Football written by Aldoshelf in 1975, mentions that football originated in China (the book was translated by a Japanese Otake Kunihiro into Japan in 1977). In the first chapter, The Birth of Football, the author compares and analyzes those activities similar to 
football in various regions of ancient Europe, including ancient Greece, Italy, England and the Americas, and then he clearly points out that numerous data show that ancient Chinese football appeared much earlier than the emergence of football in Europe and the Americas. In 2697 BC, the era of the Yellow Emperor, the football game appeared in China, and people called it Cuju. Until the end of the Zhou Dynasty in 256 BC China, Cuju was popular not only among soldiers, but also among the public. The book also stresses that Cuju was very popular in the capital of the State of Qi (ancient China), Linzi during the rule of Xuan King(301 BC) at the end of the Warring States Period. And this assertion was quickly recognized by the authorities of FIFA. In 1978, then president of FIFA, Dr. Jean-Marie Faustin Goedefroid de Havelange declared that, "International football experts had proved that football originated in China.” Then, in the training class organized by the Asian Football Confederation in April 1980, the president of FIFA, Mr. Blatter said, "Originated in China, football was introduced into the Middle East through wars waged by Alexander, and then entered the ancient Greece, Rome, France and England.” All of these can be seen in his report, The History of Footbll. In 1991, Juan Antonio Samaranch Torelló, then president of The International Olympics Committee also mentioned that, "The earliest form of football is a Chinese game called Cuju."

\section{The Development of Modern Football}

The modern football started in the ancient Greece and Rome. In the middle age, a kicking and throwing game called "harpastun" became popular among ancient Greeks. In such games, the objective of both sides is to pass the ball across the other side's line. In the 4th century BC, football was brought into the Middle East because of wars waged by the ruler of Alexander, King of Macedon of ancient Greek. Then it spread to Rome, and developed into a competitive game, of which the goal is to bring the ball to the end of the other side's zone. Due to wars, it entered France and then England in 1066. The first football club, Sheffield Football Club was found in England in 1875, followed by Austria, Spain, Italy, Hungary, the Czech Republic and Slovakia, etc. The representatives from 11 football clubs of England met in London and set up the first football organization, the Football Association on 26th, August, 1863. The foundation of FA marked a new stage of world football, so that the day was known as the birthday of modern football. The uniform contest rules were modified and laid down at the meeting. The rules only included 14 items, nevertheless, they were the base of modern football games and promoted the development of modern football. In 1872, the Football Association started organizing Winners' Cup, and modern football became widely popular in England. In 1888, the first football league in the world was held in Scotland(Gueldenpfennig, Sven, 2015.). In 1893, the football league was held in South America for the first time. In 1894, football entered into Brazil. With competitions and exchange among countries increasing, it was an urgent need for an international football organization to coordinate and organize the activities. Under this condition, Fédération Internationale de Football Association(FIFA) initiated by France, Switzerland, Sweden, Belgium, Spain, Denmark, the Netherlands and other countries was found on May 21, 1904 in Paris. Since then, the world football association has been constantly established, and the member states have increased from 7 to the 209 in 2015. Since then, modern football entered into a glorious era. The development of western modern football was driven by its industrial culture. In current historical context, the western industrial culture has become the world's dominant culture, hence modern football has become one of the most popular modern sports, and the representative of modern Western sports culture together with Olympic Games.

In the 21st century, with the growing popularity of football, the Asian Football Confederation decided to hold the Asian Cup in China in 2004. On February 4 this year, the FIFA Deputy 
Secretary General Jérôme officially announced at a press conference held in London, "Many countries believe they are the birthplace of football, but historians studying the international football have definite evidence to prove that football originated in China_- the ancient Chinese Cuju is the origin of football." He added, "FIFA will officially recognized China as the birthplace of football during the Asia Cup this summer, and we will express our respect for Chinese football by this ceremony." On May 8 the same year, when attending the 50th -anniversary celebration of the AFC in Kuala Lumpur, FIFA president Mr. Blatter awarded Chinese Football Association a trophy, symbolizing that "football originated in China." He also hoped to visit the birthplace of football when promoting the concept. Football originated in China, then, where is the exact place? Strictly speaking, the People's Republic of China has been founded for more than 50 years, but the exact birthplace of football in China has not been studied yet. According to historical materials, Linzi City of Shandong Province was recorded to be the first area to carry out Cuju activities 2300 years ago. On June 9, 2004, the expert reasoning conference with the theme of "Football Originated in Linzi” was held in Linzi. A total of 36 people attended the meeting, including experts researching on Chinese sports history, archeology, and Qi culture, sports experts in universities of Zibo, and the heads of Chinese Football Association, the committee of culture and history of State Sports General Administration. The meeting discusseded over the archaeological findings, historical records, the history of world sports, football history and other related historical materials. After two days of full argument, they finally drew a conclusion. Mr. Bai Yunxiang, the deputy director of the Institute of Archaeology of Chinese Academy of Social Sciences(CASS), on behalf of all experts and scholars of Committee announced, "ancient Chinese Cuju (football) originated in Linzi, the capital of State of Qi during the Spring and Autumn period of ancient China." On July 15 in the same year, at opening ceremony of the third China's International Football Expo held in Beijing Exhibition Center, the FIFA president Mr. Blatter solemnly declared to the world, "China is the home of football." "As the home of football, China has brought the world the most beautiful things." The secretary general of Asian Football Confederation, Veerapan addressed the press conference, "The world should give thanks to Chinese football because China is the birthplace of world football. The game belonging to ancient Linzi people now becomes a popular sport in the world.” Subsequently, Veerapan issued a certificate to Linzi, Zibo city.

However, from the perspective of academic discussions, there still exists controversy about the origin of world football. For example, the studies of World sports history have shown that various ball games have appeared in many places of the world two thousand years ago. On July 15, 2004, at the press conference of the third China International Football Expo held in Beijing Exhibition Center, a Western reporter asked the secretary general Veerapan about the assertion of "world football originated in China", "Egyptian culture is as splendid as Chinese culture and ancient Egypt had similar football sport, why wasn't Egypt chosen as the birthplace of world football?” Veerapan immediately explained to the reporter, "Many countries want to be the birthplace of football around the world. Egypt is one of them, however, only Chinese people have shown sufficient evidence.” In addition, when the deputy secretary of Zibo city municipal committee, Yue Changzhi attended the World Cup in Germany in 2006, a Scottish friend said, "The academic research on the origin of football will last for many years in the future. Modern golf originated in Scotland, where football objects 600 years ago were found." and so on and so forth. It can be said that the discussions about the origin of world football cannot be stopped only by a few words of FIFA. Many people from different countries still conduct researches on it, including British, Greek, Brazilian, Australian and so on. For example, during the recent exhibition of football charm in Hamburg, a western reporter interviewed the curator of Hamburg Museum of Ethnology, Orff Keparker, "Who invented football on earth?” Professor Keparker replied, “In fact, the European, South American, Chinese, Japanese, Indonesians, Australians and even Eskimos started to play various forms of football long ago. 
However, according to the study of sociologists in Peru, Chinese people first invented football, the British improved the rules of playing football, and Brazilian made it a popular sport. In other words, it's the joint efforts around the world that created today's modern football."

\section{Conclusion}

Cuju and football are two concepts of the same thing. The relation between ancient Chinese Cuju and modern football should be closely connected and indivisible. It is natural for ancient Chinese Cuju to develop into modern football. However, due to China's long-time feudal autocracy and the slow development of social economy dominated by agricultural economy, ancient Chinese Cuju disappeared after its popularity for several thousand years. While modern football, which originated in England, has gradually become one of the most popular sports around the world with industrial economy booming.

As a result of the Opium War in modern times and the destruction of Chinese feudal society, the traditional Chinese sports lost their momentum of development on the world stage and gradually disappeared. Similarly, With the end of the Cold Weapon Age, the development of the fighting skills of Chinese Wushu is gradually dying out.

\section{Acknowledgements}

This paper is supported by "Project of the humanities and social sciences research program of the Ministry of education of China" (15YJA890016), Basic scientific research projects in Chinese Universities (2-9-2015-417) and China University of Geosciences (Beijing) key project of teaching reform (JGZHD201711).

\section{References}

[1] Gorman, Sean. Judd, Barry. Reeves, Keir. 2015. Aboriginal Rules: The Black History of Australian Football, International Journal of the History of Sport, 16 (32), pp. 1947-1962.

[2] Gueldenpfennig, Sven, 2015. The History of the Football Federal League, International Journal of the History of Sport. 2 (32), pp. 372-375.

[3] Kitching, Gavin, 2015. The Origins of Football: History, Ideology and the Making of “The People's Game”, History Workshop Journal.79, pp. 127-153.

[4] Sima Qian, 1978. Records of the Historian, Zhonghua Book Company. Beijing, 1st edtion.

[5] Wood, David, 2015. An Illustrated History of Caribbean Football, International Journal of the History of Sport. 15

(26), pp. 2284-2287.

[6] Xiang Liu, 1975. Bie Lu, Zhonghua Book Company. Beijing, 1st edtion. 